\title{
WHAT IS OFFENSIVE ABOUT OFFENSIVE JOKES?
}

\author{
Jeanette Bicknell
}

There is an element of malice in much humor. (That slipping on a banana peel is funny does not make the fall any less painful, after all.) A good deal of our laughter in comedy is directed at misfortune, presented in such a way as to elicit amusement rather than outrage, tears or compassion. One need not be a Freudian to recognize the element of hostility in certain jokes; and Bergson's remark that comedy requires a "momentary anesthesia of the heart" is surely plausible. ${ }^{1}$ This might tempt one to draw gloomy conclusions about human nature; yet few would insist, I suspect, that we eradicate all of the nastiness from our humor. However even fewer would argue that joking be set completely free from moral restraint. Joking is a social activity; it involves and implicates others whether as audience or as butts. $^{2}$ It is subject to moral consideration and assessment. Joking, we judge, is sometimes inappropriate, and on moral grounds. Jokes themselves range along a continuum, from those that are totally innocuous from a moral point of view, to those that should probably not be repeated. While we might come to broad agreement over which jokes are morally inappropriate, it is no simple matter to say when a joke is offensive, what makes an offensive joke offensive, and to determine where the moral fault lies when there is one. In what follows I will discuss several attempts to do just this.

In the small philosophical literature on the morality of humor, we can discern two dominant positions: (1) a cognitivist or belief-based position and (2) a consequentialist one. Writers often incorporate elements of both positions, but they can be separated for the purpose of analysis. Worthy of note yet not fitting into either category is (3) Ted Cohen's recent antitheoretical account of the morality of offensive jokes. ${ }^{3}$ In this essay I argue that the cognitivist position is fundamentally flawed as an account of the immorality of offensive jokes. The consequentialist position is more adequate but ultimately unsatisfactory; the moral deficiency of offensive humor is not exhausted by its consequences or possible consequences. I suggest, contra Cohen, that the ethics of humor

PHILOSOPHY TODAY is an appropriate area of theorizing, and propose an account of the moral fault of offensive jokes that is broadly within the virtue ethics tradition. ${ }^{4}$ My account can be taken both as a stand-alone account of the morality of offensive jokes and as a necessary supplement to the consequentialist position. I should say at the outset my conclusions will not be framed in the language of necessary and sufficient conditions. As Aristotle cautioned, precision is not to be sought for alike in all discussions. Joking is one of those subjects for which we can indicate the truth only roughly and in outline. ${ }^{5}$

Why is this topic worthy of philosophical consideration? Is it not trivial, given the problems that usually vex moral philosophers? Philosophers seem to me all too reluctant to address the morality of "everyday life." Yet this is precisely the subject of much ordinary reflection on right and wrong. The tools we use to sort out the morality of weightier and more public topics can be put to good use here. It may even turn out that the morality of smaller everyday issues will illuminate bigger problems. An additional sort of objection to taking the morality of jokes seriously is that offended responses to humor say more about those who take offense than it does about the jokers. Those offended, such an objection runs, should learn to "take a joke," get a "sense of humor," and "laugh at themselves." Yet such an objection is itself a moral claim and as such requires argument. It may indeed be the case that some of those wounded by offensive jokes are inappropriately or excessively sensitive. But I doubt this could be true in every instance or in response to any joke, however malicious.

I am particularly interested here in jokes at the expense of an individual or group based on race, gender, ethnicity, religion, sexual orientation, or physical or cognitive ability. While there are other types of jokes that may be in poor taste and may also offend (black humor, "gross-out" humor), I shall not consider them here. I will limit my discussion to jokes and witty remarks among friends and colleagues, rather than jokes by professional entertainers. The social context of these two types of joking

WINTER 2007 
seems to be importantly different. If you find the humor of Sacha Baron Cohen, Chris Rock, or Bernie Mac to be offensive, you need not subject yourself to their performances. The situation is rather different with remarks bandied about in the locker room or at a department meeting where one is not always free to absent oneself. This is not to say that the activities of professional comedians are morally innocuous; just that the issues raised are significantly different so as to call for separate treatment.

One further clarification: Following other writers in this area, I take very seriously the social context and ramifications of joke telling. Thus my interest here is not in jokes as literary forms or types, but in specific joke tokens told in certain contexts. So I am concerned not with the genres of jokes about blacks or homosexuals or Jews, but in the telling and re-telling of such jokes in particular social settings. A joke or remark cannot be morally judged outside of its context. A joke at the expense of Group X told among members of that group will have a different resonance and significance when told by members of Group Y (whether among themselves or to others). ${ }^{6}$

\section{The Cognitivist Position}

This type of account centers on connections between jokes and cognitive states: beliefs and attitudes underlying or incorporated into jokes; beliefs required to find jokes funny; purported beliefs of those telling the jokes in question. Moral culpability, on such an account, lies in the holding of certain offensive beliefs. One objection is that such an account cannot get off the ground, since moral responsibility is a matter of deeds rather than beliefs or attitudes. While I am sympathetic to this objection, I will not pursue it here.

Hugh LaFollette and Niall Shanks develop a theoretical account of humor such that what we find humorous depends on what beliefs we hold. A joke that belittled women could be humorous only to someone who had the appropriate sort of higher-order beliefs ("women are mentally or morally inferior to men.") What is offensive, they argue, is not the joke itself, but the underlying beliefs and attitudes of its teller and those amused by it. One unexamined implication of their account is that it makes the non-joking espousal of racist or sexist beliefs morally equivalent to telling racist or sexist jokes. While this may in fact be so, such a view needs to be defended rather than assumed from the outset.

However there are good reasons to believe that the joking and non-joking espousals of offensive beliefs are importantly different and subject to different moral assessments. For one thing, jokes are fictions and are understood to be such by joke tellers and audiences. (This point has been recently emphasized by Noël Carroll and, especially, Ted Cohen.) If someone begins a joke with the words, "An elephant walked into a bar ....," listeners do not say, "Wait - an elephant couldn't do such a thing." Rather, they suspend disbelief and anticipate a punch line. Furthermore-and this is acknowledged by most participants in the debate-being aware of offensive beliefs or stereotypes is not the same as holding them. It seems possible to laugh at Polish jokes, blonde jokes, or Newfie jokes without harboring any negative beliefs about Poles, blondrs or Newfies. Indeed, Carroll has written that when he heard his first Newfie joke, he didn't know what Newfies were and so had no beliefs about them. ${ }^{7}$

A subtle defense of the cognitive position has been offered by Ronald DeSousa. He argues that the presuppositions and beliefs that underlie say, malicious sexist jokes, are different from those that underlie innocuous jokes like the above elephant example. In order to find a malicious joke funny, the listener must actually share its underlying emotional attitudes. While one can hypothetically adopt or suspend beliefs (such as the belief that an elephant could not walk unaided into a bar), one cannot hypothetically adopt or suspend an emotional attitude. So if a person takes pleasure in or is amused by a joke trading on negative stereotypes of blondes, he or she must have an underlying negative emotional attitude towards them. Someone who does not have this attitude would not find jokes about blondes to be funny.

DeSousa's position has been both endorsed and criticized, which discussion I will not rehearse here. ${ }^{8}$ I do not find DeSousa's key theoretical claim - the cognitive separation of belief from attitude-very compelling, or indeed, very helpful. Attitudes and beliefs inform one another. The beliefs I have about ele- 
phants will influence the attitude I take to them; my attitudes will color the beliefs I take up. Furthermore, attitudes would seem to be more rather than less subject to voluntaristic control than are beliefs. We speak ordinarily and unproblematically of adopting attitudes and of trying to maintain a positive attitude in the face of adversity. Holding a vigorous "ethics of belief" means maintaining an attitude of dubiousness and incredulity. ${ }^{9}$ While we may suspect that judges privately hold beliefs about the parties they adjudicate, we expect them to set aside such beliefs and maintain a "judicial attitude."

It is far from clear that all those who enjoy offensive humor share morally inappropriate attitudes to the butts of these jokes. The moral defect in offensive jokes must lie elsewhere than in their connection to offensive beliefs or emotional attitudes.

\section{The Consequentialist Position}

According to consequentialist accounts, certain jokes are morally suspect because of the harm they cause or are likely to cause. The recipients of harm are most likely to be those joked about, but joke tellers and audiences may also suffer harm. If it could be shown that offensive jokes do cause harm, we would know where at least some of their moral defect lies. I hope to show that the moral impropriety of offensive humor is not exhausted by possible consequences of these jokes. The virtue ethics position I will develop in the final section of this essay is a necessary supplement to any consequentialist account.

Michael Phillips argues that laughter at offensive jokes binds joke teller and audience into a community, and that this mutual participation-even shared intimacy_legitimates offensive feelings and beliefs. ${ }^{10} \mathrm{He}$ writes, "By appreciating such humor together, we take common joy in putting them down, e.g., in turning them into objects of scorn or contempt or into beings not to be taken seriously." But Phillips presupposes here that shared laughter in a joke requires shared attitudes. As argued above, the fact that someone finds an offensive joke to be funny does not necessarily indicate that he or she shares the joke's presuppositions. I can be aware of stereotypes - the drunken Irishman, the ditzy blonde, the tightfisted Scot-without endorsing them.

If we accept that sharing jokes can engender and develop intimacy between teller and audience, we would have to acknowledge that racists and sexists may cement their fellowship with those likeminded through the use of offensive humor. This would certainly be a bad consequence of racist or sexist humor. But the difficulty here is that almost anything racists or sexists do together and any conversation they have might serve to engender intimacy among them. There seems little reason to think that joke telling is uniquely and specially suited to the development of intimacy. Other activities and topics of conversation, for example sharing perceived grievances against outsiders, may be even more effective than shared jokes for the purposes of engendering intimacy. So there would seem to be no reason for offensive jokes as jokes to receive special moral rebuke.

Phillips also argues that, "one promotes racist beliefs by means of racist humor when one lends one's authority to a joke that embodies some racist stereotype." However the teller of a joke does not necessarily lend authority to anything. One's response to a joke and one's assessment of the joke teller depend on many factors: levels of intimacy and mutual understanding, dynamics of power, the presence or absence of others, and the social context more generally. Depending on your antecedent beliefs about a person and your attitude toward those who tell offensive jokes, you might very well think all the less of him or her for repeating an offensive joke. ${ }^{11}$

David Benatar also defends a consequentialist account of offensive jokes. ${ }^{12} \mathrm{Hu}-$ mor is immoral where it is intended to harm or can reasonably be expected to harm, and where the harm is wrongfully inflicted. His argument takes off from the claim that, together with an interest in being treated well, we all have interests in being well regarded and having good reputations. Jokes that reinforce negative stereotypes about us, or which demean or mock a group we are part of, adversely affect these interests. So immoral humor infringes the butts' interests in not being demeaned, insulted, shocked, and so on. Jokes that spread say, racist views, are harmful even if the person who tells them does not endorse the stereotypes they embody. Although the harm suf-

\section{PHILOSOPHY TODAY}


fered by the butt of offensive jokes may be slight, it would be a mistake, Benatar claims, to fail to distinguish between small harms and the absence of harm. ${ }^{13}$

Benatar does not suggest that jokes at the expense of a racial or other marginalized group are always out of bounds. He distinguishes (morally offensive) racist and sexist humor from (morally inoffensive) racial and gender humor. These latter types of jokes turn on racial and gender stereotypes but are not intended, or cannot be reasonably expected, to inflict harms on racial or gender grounds. ${ }^{14}$ The main difference between these two types of jokes seems to be that listeners can enjoy innocuous racial and gender humor without actually endorsing the stereotypes embodied by the jokes. Since racial and gender humor does not necessarily express prejudice, these jokes are not necessarily morally defective. Benatar however reminds his readers of the "unpleasant fact" that racial and gender humor does in fact often express or reinforce prejudice, causing people to be insulted or demeaned. ${ }^{15}$

Benatar's account has the advantage that he does not need to make a case that offensive jokes cause harm or have additional negative consequences beyond adversely affecting the interests of those who are at the butt of the jokes. One difficulty with his account is that there seems to be no way, in the end, to decide under what conditions a joke might be appropriate and when it would be morally problematic. Even though racial and gender humor do not necessarily express prejudice, they might still cause people to be harmed (insulted or demeaned). Are the demands of moral sensitivity such that racial or gender humor can never be enjoyed? Before I develop my own account, I turn to Cohen and the worry that a theoretical account of such matters is not possible.

\section{Cohen and the Limits of Theory}

Cohen, who describes himself as someone who tells too many jokes too often in too many kinds of situations, finds himself disturbed by certain offensive jokes. He wonders whether his personal discomfort and disapproval could be generalized and made "objective" so that we could make a negative assessment of the jokes themselves. He suspects that the jokes he finds disturbing would remain disturbing even if it could be shown that they cause no harm and have no harmful effects. Yet his overall conclusion is negative; in the end Cohen believes that his dislike of such jokes comes to nothing more than a wish to be free of them. However Cohen is not greatly troubled by his conclusion. If you feel a joke to be disturbing - if a joke arouses your moral hacklesthat is a sufficient basis for action. You do not need a theory to explain your conviction and should not be concerned that you cannot offer one. It is entirely within your rights, on the basis of your feelings, to avoid tellers of offensive jokes or ask them not to tell such jokes in your presence.

I take Cohen to be making at least two different but related claims. First, we do not need a moral theory to validate our feelings of discomfort at certain offensive jokes. Second, even if we did need such a theory, none could be given. In the next section of the paper I will address Cohen's second point and try to offer a theory of why we find certain jokes to be offensive. But before that, let me say something about Cohen's claim that such an explanation is not needed.

In one sense, Cohen is surely correct. Just because I cannot explain why your behavior disturbs me it does not follow that I must endure it. I can ask you to stop, and if you care about me or about social peace, you will comply. But in another sense, we do need a moral theory. When something disturbs us, and the reason for our distress is not readily apparent, we usually want to know why. We want our distress explained; and I would say that only as a last resort do we conclude that the distress is a fact about us, not a fact about the efficient cause of the distress. Moreover, when we experience moral disgust, we desire and expect that others-especially others we care aboutshare these feelings. When we "smile at the good and frown at the bad" we want others to smile and frown along with us. We want our moral reactions vindicated and endorsed; in other words, we want them explained, and if possible, justified.

\section{Jokes and the Morally Informed Life}

In the previous section, I found Cohen's conclusions on the limitations of moral theory with regard to jokes to be bracing, but ulti- 
mately dissatisfying. Yet one of his remarks on the subject hints at a possible solution:

A common, sometimes useful device in analytical, conceptual moral theory is the idea of an ideal creature, sometimes called an ideal observer, or an impartial spectator, or a person of practical wisdom. First, such a creature is characterized (perhaps as being completely informed, disinterested, and so on), and then it is supposed that the right way to act, or to feel, or to judge, is to act, feel, or judge as this ideal creature would. Try thinking up such a person, and then ask whether this person would disapprove of these [offensive] jokes, whether he would tell them or laugh at them, and how he would feel about anyone who tells them. What do you think? Would he damn these jokes? I don't know, and neither, I think, do you. ${ }^{16}$

Cohen is speaking here of a general methodological and meta-ethical device-an ideal observer, impartial spectator, or person of practical wisdom. Each of these would get the job done, but in a different way. Let us consider just one such figure - an Aristotelian person of practical wisdom or phronimos. Such an individual has the capacity for deliberating well about what contributes to the good life in general (1142a24-7). Significantly for my concerns here, he is adept at discerning just actions and the particulars of how to live (1140a25-8).

Would a phronimos tell jokes and enjoy hearing jokes told by others? There is good reason to think so, as Aristotle includes wit or cheerfulness among the virtues; it is the mean between the vices of boorishness and buffoonery. It is worth quoting the Nicomachean Ethics here:

Since relaxation is a part of life also, and in relaxation one may pass the time with amusement, it seems that here too there may be a social relation with propriety in which one says the right things and in the right manner, and similarly when one listens to them. There will also be a difference with respect to the kind of people one is speaking or listening to. So it is clear that concerning these, too, there is an excess and also a deficiency beyond the mean. Thus those who are beyond propriety in matters of humor are thought to be buffoons or vulgar,

\section{PHILOSOPHY TODAY}

eager to be humorous by any means and aiming at causing laughter rather than saying what is proper or causing no pain to the one laughed at. (1127b35-1128a6)

So Cohen's skepticism (at least with respect to the person of practical wisdom) is unjustified. For someone striving to live a virtuous life, certain reactions will be discouraged and certain actions will be out of bounds, including telling some jokes in some contexts. Both in telling jokes and in responding to them there is a right way and a wrong way, a vice of excess and a vice of deficiency. Telling a joke is a type of action, and telling a malicious joke-one which causes pain to the person or persons laughed at - can be a malicious action, whether the joke is funny or not. It may not be a simple matter to decide which jokes are vicious and hence out of bounds; moral questions, even the ethics of "everyday life," are notoriously difficult. But that does not mean that the question is in principle impossible, as an uncharitable interpretation of Cohen's remarks might imply.

Which jokes at the expense of others are innocuous fun and which are malicious? A look at our social conventions and practices around joke telling can help answer this question. I find it significant that some groups can be joked about with impunity. Singers tell jokes about the alleged stupidity of tenors; orchestra musicians tell jokes about the inability of violists to play in tune; and almost everyone tells jokes about the venality of lawyers. I think it unlikely that anyone would be offended or made uncomfortable by such jokes (excepting perhaps the extremely sensitive, or instances in which the joke was part of an on-going campaign of harassment). If any member of one of these joked-about groups were to protest, I doubt that we would give their protests much moral weight. What are the differences between these groups and others whom we might be uncomfortable joking about? How, if at all, are lawyer jokes different from jokes about Jews, blacks, women, homosexuals, or the disabled?

One possible answer is that being a professional singer or viola player is voluntary, while being a member of one of these other groups is not. Thus in making jokes about the latter groups, one may threaten the self-esteem and 
sense of identity in ways we do not when we joke about the former groups. While this response has some plausibility, the moral offense in offensive jokes is not in the fact that the groups being mocked are not freely joined and thus constitutive of identity. I can imagine someone who identified as strongly with her profession as with her ethnicity or race. And I would not want to tell her that one was more important or constitutive of self than the other.

I submit that the vulnerability of the group or individual joked about is the main factor in determining whether and to what extent a joke is morally offensive. It should not be controversial that certain groups in society are more vulnerable than others, and that there are various ways in which certain individuals or groups might become more vulnerable than they had been previously. The weak or credulous in any society are vulnerable to the unscrupulous. Other groups may be vulnerable because a history of prejudice against them taints current attitudes. Others may be subject to hostility for a variety of reasons, legitimate or not. Still others are at risk of injury (if only emotional injury) because of general ignorance, whether well-meaning, indifferent, or hostile, about their way of life and the challenges they face. The issue of who in a given society is or is not vulnerable, then, is not wholly objective and is subject to change over time. The reason why jokes about lawyers, say, are largely morally innocuous is that lawyers are not generally taken to be a vulnerable group. That is to say, we do not take lawyers to be susceptible to injury, whether physical or emotional, simply in virtue of being lawyers. The lawyer who claims vulnerability is liable to be thought "overly sensitive."

What is wrong, then, with telling jokes at the expense of marginalized groups is not just that these jokes constitute harm, or that such humor may cause further harm (consequentialism), or that the underlying beliefs of those who tell or enjoy such jokes are morally suspect (cognitivism). The moral fault in telling such jokes lies either in the failure to take account of vulnerability in others, or in the decision to exploit such vulnerability for the sake of humor. Telling a joke about a vulnerable group is a little like kicking someone when she is down. Assuming that the person is already down and cannot be harmed further, what is wrong with kicking her again? I am afraid that no better answer can be given than such actions are inconsistent with attempts to live a virtuous or morally informed life. ${ }^{17}$

As I have outlined it, a virtue ethics position on the ethics of humor has advantages over both the cognitive and consequentialist accounts. A cognitivist must make several claims about others' beliefs and attitudes. At the crux of their position is the question of to what extent those who laugh at or tell offensive jokes accept the stereotypes underlying the jokes. On a virtue ethics position, we need not venture into the murky territory of others' mental states. Second, for the consequentialist position to be plausible, it must be shown that offensive jokes tend to cause harm or that being the butt of a joke is in itself a harm. However it is extremely difficult to demonstrate that offensive humor, unpleasant though it can be, has harmful consequences. Even if we accept that being the butt of a joke is in itself a harm, the virtue ethics position I have outlined still has value as a necessary supplement.

A virtue ethics approach also has advantages over a deontological account (such that telling certain types of jokes would be inherently immoral and out of bounds). The approach I have outlined is sensitive to context and would not condemn jokes told by a marginalized group about themselves. Such humor may have a salutary effect such as encouraging group solidarity in the face of adversity. Where stereotyping is involved, self-stereotyping is a means of exploring identity in the eyes of the self and the other. This is not to say that any jokes told within marginalized groups are innocuous. If, say, Jewish women are vulnerable as women within the Jewish community, then jokes at their expense by Jewish men would be called into question.

The status of groups can change over time, and my position is sensitive to this. If it ever came to be the case that lawyers qua lawyers or tenors qua tenors were persecuted or vulnerable, then jokes about them would no longer be innocuous. Jokes and humorous stories age particularly poorly as literary forms. At the "Museum of Humour" in Montreal, Canada on display are filmed comedy routines from the earliest days of cinema to the present, including stand-up routines, short films, extracts from movies and TV shows, and filmed theat- 
rical pieces. While some of the material is still funny, much of the remainder is cringe-making. The Museum also functions in this way as a repository of changing social attitudes. We seem to be now embarrassed or made uncomfortable by the same things that our parents and grandparents apparently found funny. No doubt the reasons why are complex; part of the explanation may be that the perception of who is vulnerable and what should or should not be made fun of, changes over time.
Finally, join me in a thought experiment. ${ }^{18}$ Imagine a world without economic or social injustice or prejudice, a world where even the memory of such injustice or prejudice is so faint as to be nearly unrecoverable. I submit that in such a world, jokes at the expense of gays, blacks, and other currently marginalized groups, would be no more troubling than lawyer jokes are to us today. ${ }^{19}$

\section{ENDNOTES}

1. Henri Bergson, Laughter: An Essay on the Meaning of the Comic. Selection reprinted in The Philosophy of Laughter and humor, ed. John Moreall (Albany: SUNY Press, 1987), 117-26.

2. Particularly good on this point is J. Harvey, "humor as Social Act: Ethical Issues," The Journal of Value Inquiry 29 (1995): 19-30. See also Peter Kivy, "Jokes are a Laughing Matter," Journal of Aesthetics and Art Criticism 61 (Winter 2003): 5-15.

3. I discuss the following: Merrie Bergmann, "How Many Feminists Does It Take To Make A Joke: Sexist humor and What's Wrong With It," Hypatia 1 (Spring 1986): 63-82; Noël Carroll, "humor," in The Oxford Handbook of Aesthetics, ed. Jerrold Levinson (Oxford: Oxford University Press, 2003), 344-65, and "Intimate Laughter," Philosophy and Literature 24 (2000): 435-50; Ted Cohen, Jokes: Philosophical Thoughts on Joking Matters (Chicago: University of Chicago Press, 1999); Ronald DeSousa, "When Is It Wrong to Laugh?" in The Philosophy of Laughter and humor, 226-49; Hugh LaFollette and Niall Shanks, "Belief and the Basis of humor," American Philosophical Quarterly 30 (October 1993): 329-39; Michael Philips, "Racist Acts and Racist humor," Canadian Journal of Philosophy 14 (March 1984): 75-96. Also relevant but beyond the scope of my discussion are Berys Gaut, "Just Joking: The Ethics and Aesthetics of humor," Philosophy and Literature 22 (April 1998): 51-68, and F. H. Buckley, The Morality of Laughter (Ann Arbor: University of Michigan Press, 2003). Gaut is concerned with whether manifesting either ethically commendable or unworthy attitudes might count for or against a joke's humor. Buckley provides a rich discussion of the role of laughter in a complete life, but says little about the questions that concern me here. I have learned from all of the sources listed above.

4. Among the positions I consider in this essay, my own view is closest to that of Bergmann, although I offer different arguments for it.
5. Aristotle, Nicomachean Ethics, 1094b12-28.

6. My interest in specific social contexts of joke telling is also the reason why I have not included any jokes in the essay.

7. "Newfies" are Canadians from Newfoundland, the final province to join Canadian confederation.

8. Harvey seems to endorse it; critics include Carroll, "humor;" Daniel Jacobson and Justin D' Arms, "The Moralistic Fallacy: On the 'Appropriateness' of Emotions," Philosophy and Phenomenological Research 61 (July 2000): 65-90; and David Benatar," Prejudice in Jest: When Racial and Gender humor Harms," Public Affairs Quarterly 13 (April 1999): 191-203.

9. The classic source is W. K. Clifford, "The Ethics of Belief," Lectures and Essays (London: MacMillan and Company, 1886), 339-63.

10. Cohen also stresses the community-building aspects of joking, and the connection between shared jokes and intimacy. See his Jokes.

11. The situation of parents telling offensive jokes within hearing of young children is more problematic, but I do not think that the general point is refuted.

12. David Benatar, "Prejudice in Jest: When Racial and Gender humor Harms," Public Affairs Quarterly 13 (April 1999): 191-203.

13. Ibid., 191-96

14. Ibid., 196.

15. Ibid., 202

16. Cohen, Jokes, 81.

17. An important qualification is that there is a range of individual variation. Some members of powerful groups claim to be vulnerable; some members of vulnerable groups take umbrage at the mildest quip. In these cases we adjust our moral compass: Depending on our concern for such individuals we may mute our attempts at humor in their presence while maintaining that, in general, their group is fair game.

18. I borrow this thought experiment from Alan Soble, who uses it in a different context. See his Pornogra-

\section{PHILOSOPHY TODAY}


phy: Marxism, Feminism, and the Future of Sexuality (New Haven: Yale University Press, 1986), chapter 3.

19. This essay had its origin in a commentary on Tanya Rodriguez, "Racist Joking: Irony and Empathy" presented at the American Society for Aesthetics
2003 Annual Meeting in San Francisco. I am grateful to her, and also to Patricia Greenspan, Ian Jarvie, and Jerrold Levinson for discussion and comments on earlier versions. Work on this essay was made possible by a Social Sciences and Humanities Research Council of Canada postdoctoral fellowship.

Carleton University Ottawa, Canada K1S 5B6 